\title{
Anxiety-Depressive Profile in Adolescent Consumers of Psychoactive
}

\author{
I. Cherkaoui El Malki'1, I. Echerbaoui' ${ }^{1}$, K. Mammadi', Y. El Madhi², A. O. T. Ahami' \\ ${ }^{1}$ Unit of Cognitive Behavioral Neurosciences \& Nutritional Health, Department of Biology, Faculty of Sciences, Ibn Tofail \\ University, Kenitra, Morocco \\ ${ }^{2}$ Regional Center of Trades of Education and Training Rabat-Salé-Kenitra, Kenitra, Morocco \\ Email:khaoula.mammad@gmail.com
}

How to cite this paper: El Malki, I.C., Echerbaoui, I., Mammad, K., El Madhi, Y. and Ahami, A.O.T. (2018) Anxiety-Depressive Profile in Adolescent Consumers of Psychoactive. Open Journal of Medical Psychology, 7, 13-25.

https://doi.org/10.4236/ojmp.2018.72002

Received: March 23, 2018

Accepted: April 27, 2018

Published: April 30, 2018

Copyright (c) 2018 by authors and Scientific Research Publishing Inc. This work is licensed under the Creative Commons Attribution International License (CC BY 4.0).

http://creativecommons.org/licenses/by/4.0/

\section{(c) (i) Open Access}

\begin{abstract}
Adolescence is a period of pivotal change in brain development. It accompanied by profound cognitive-behavioral, somatic and psychic changes with increased vulnerability to risk taking. This work explores the current state of consumption of the main psychoactive substances (PAS), (tobacco, cannabis, alcohol) among schoolchildren, their interrelationships and the possible links with psychological suffering of anxious or depressive type. The study is a descriptive and analytical transversal type, carried out by a self-questionnaire and two neuropsychological tests evaluating depressive symptomatology: Adolescent Depression Rating Scale (ADRS) patient version in 10 items, and The Hospital Anxiety and Depression Scale (HADS), among 714 high school students aged 15 to 21 years, in Kenitra, Morocco. The results show that the population of adolescents who use psychoactive substances appears to be more depressed and more anxious than non-users. The prevalence of regular consumption of the three psychoactive substances is significant between girls and boys $(\mathrm{p}<0.000)$, and shows that for: tobacco is $16.38 \%(14.52 \%$ girls, $85.47 \%$ boys); cannabis is $6.72 \%$ ( $1.7 \%$ girls, $95.83 \%$ boys); and alcohol is $5.88 \%$ (2.56\% girls, $92.86 \%$ boys). These results encourage an emphasis on the school's role in early detection of adolescent-specific pathologies such as anxiety and depression. As well as the development of strategy of prevention of consumption of the PAS, and the care of the pupils presenting anxious or depressive symptomatology. In addition, further longitudinal studies would be needed to establish causal links among anxiety, depression, and PAS use.
\end{abstract}

\section{Keywords}

Adolescence, Psychoactive Substances, Depression, Anxiety, Morocco 


\section{Introduction}

Adolescence is a period of pivotal change in brain development. It accompanied by profound cognitive-behavioral, somatic and psychic changes with increased vulnerability to risk taking. Otherwise, according to studies conducted in the United States and Australia, depressive disorders affect between 11\% and $48 \%$ of adolescents with a disorder related to the use of a psychoactive substance and anxiety disorders affect between 7\% and 40\% [1] [2] [3] [4]. Depression in adolescence is associated with several factors such as absenteeism and school failure, risky sexual behaviors, relationship difficulties and substance abuse [5]. In fact, depression remains an important risk factor for nicotine addiction [6], tobacco, alcohol and cannabis are the substances most commonly consumed by adolescents [7] [8] [9] [10]. Moreover, adolescence is considered a risk period for the consumption of psychoactive substances [11]. Thus, the latest Mediterranean School Survey Project on Alcohol and Other Drugs (MEDSPA) report (2014) [12] indicates that the prevalence of the use of different psychoactive substances among Moroccan adolescents aged 15 to 17 is as follows: Tobacco 17\%, Alcohol 9\%, Haschich $9 \%$.

Several studies in Morocco have focused on assessing the prevalence of psychoactive substance use in different populations of school-aged adolescents and studying its relation to socio-economic and cultural characteristics [12] [13] [14] [15] [16]. But rare are those who have addressed the possible links between this problematic use of these PAS and some specific pathologies to adolescents such as depression, anxiety. In order to provide elements to remedy this lack of data, this work explores the current state of consumption of the main psychoactive substances (PAS), (tobacco, cannabis, alcohol) among schoolchildren, their interrelationships and the possible links with psychological suffering of anxious or depressive type.

\section{Method}

The study is a descriptive and analytical transversal type. It was built in the Kenitra city, Morocco, covering an area of $76 \mathrm{~km}^{2}$, it is the fourth industrial city of the country, in the North West of Morocco, with more than one million inhabitants. It took place in January 2018. The protocol given to each subject consisted of a self-questionnaire, and two neuropsychological tests: Adolescent Depression Rating Scale (ADRS), and The Hospital Anxiety and Depression Scale (HADS).

\subsection{Participants}

The sample consists of 714 ( 430 boys and 284 girls) subjects of adolescents population from high schools of different sectors. The mean age was 17.39 years $(\mathrm{SD}=$ 1.47), range: 15 and 21 years (Table 1). Moreover, the participants were selected because they reflect a representative sample of the adolescents population's study of high schools in Kenitra (which is selected randomly). Our sample 
Table 1. Distribution of subjects by sex and age.

\begin{tabular}{ccccc}
\hline & \multicolumn{4}{c}{ Distribution of sample by sex and age } \\
\cline { 2 - 5 } & $\mathrm{n}$ & $\%$ & Mean of age (SD) & Extended \\
\hline Girls & 284 & 39.8 & $17.42(1.27)$ & $15-21$ \\
Boys & 430 & 60.2 & $17.38(1.60)$ & $15-21$ \\
Total & 714 & 100 & $17.39(1.47)$ & $15-21$ \\
\hline
\end{tabular}

divided into three sections: modern letters, experimental sciences (biology, geology, physics, and chemistry) and mathematical sciences.

For ethical considerations, participants informed of the anonymity of the study and the possibility of refusal to participate. While the self-questionnaire explained the interest of the study, its anonymity and the possibility of refusal of participation. The agreement of the provincial delegates of the Ministry of National Education and Vocational Training and the directors of the establishments concerned was obtained.

\subsection{Measures}

\subsubsection{Self-Questionnaire}

The questionnaire on the collection of data on participants, with 31 items, recorded the student's sociodemographic information and the taking of different PAS (tobacco, alcohol, cannabis).

\subsubsection{The Adolescent Depression Rating Scale (ADRS)}

The scale measures the depressive intensity. It intended specifically for adolescents aged 13 to 20 years [17]. This promising, easy-to-use dimensional tool intended to identify the depressive experience and measure intensity of depression in adolescents. The internal validity of the 10 item version (yes/no) of the ADRS is high (>0.8) and the discriminant validity is also good.

\subsubsection{The Hospital Anxiety and Depression Scale (HADS)}

Zigmond's self-questionnaire, and Snaith (1983) [18] is a test that assesses depressive and anxious symptomatology over the past week, and assesses its severity; by ruling out somatic symptoms that could distort re-evaluation in patients seen in medicine (and frequently having organic problems). The 14 items are divided into two subscales: 7 items to evaluate depression: one for dysphoria, one for slowing down and five for the anhedonic dimension; and 7 items to assess anxiety from the Present State Examination [19] and the Clinical Anxiety Scale [20]. For each item, four answer modes coded from 0 to 3 and the higher the scores, the more severe the symptomatology.

\subsection{Procedure}

This study took place in high schools in the Kenitra city of Morocco. We collected the data in the form of group handouts in a school classroom with 20 students, in the presence of the investigator with the objective explanation of the 
study. Both tests were translated into Arabic and, if necessary, some questions were explained in simple terms and accessible to all (in dialectal Arabic). To avoid any bias, a period outside exams, parties and school holidays was chosen. The investigation began on January 13, 2018 and lasted 6 days.

\subsection{Statistical Analysis}

Coding, processing and statistical analysis of the data were done with Excel 2013 software and SPSS V.17 software. The statistical tests used were: $\chi^{2}$ and Student's t-test. The tests were considered significant for a degree of significance "p" less than or equal to 0.05 .

\section{Results}

\subsection{Prevalence of Psychoactive Substance Use}

Regular consumption of tobacco is $16.38 \%$ (14.52\% are girls and $85.47 \%$ are boys); cannabis is $6.72 \%$ ( $1.7 \%$ are girls and $95.83 \%$ are boys); and alcohol is $5.88 \%$ (2.56\% are girls and $92.86 \%$ are boys). The $\chi^{2}$ test allowed us to highlight a significant difference between girls and boys regarding the prevalence of consumption of the three PAS (Table 2).

\subsection{The Hospital Anxiety and Depression Scale (HADS)}

From the scale, anxiety and depression scores were found to be higher among student consumers $(\mathrm{M}=16.57 \pm 5.87(0-28))$ than non-users $(\mathrm{M}=14.4 \pm 4.60$ $(0-27))$. Student's $t$ test allowed us to show a significant difference between non-consumers and consumers $(\mathrm{t}=4.309, \mathrm{p}<0.000)$ (Table 3$)$.

\subsubsection{Anxiety Disorders}

Anxious symptomatology is more present in consumers than in non-consumer subjects $(\mathrm{t}=8.669, \mathrm{p}<0.001)$, the majority of non-consumers $(81.28 \%)$ do not have an anxiety disorder, compared to $54.7 \%$ of tobacco users, $70.83 \%$ of cannabis users and $69.05 \%$ of alcohol users. One-tenth $(10.83 \%)$ of non-consumers have suspicious anxiety disorders, compared to $29.06 \%$ of tobacco users and $20.83 \%$ of cannabis users and $21.43 \%$ of alcohol users; and only $7.89 \%$ of non-consumers with anxiety disorders, compared to $16.04 \%$ of tobacco users, $8.33 \%$ of cannabis users and $9.52 \%$ of alcohol users (Table 3 ).

Table 2. Prevalence of psychoactive substance users in schools.

\begin{tabular}{|c|c|c|c|c|c|c|c|c|}
\hline \multirow{4}{*}{ Regular consumption } & \multicolumn{8}{|c|}{ Consumption of psychoactive substances } \\
\hline & \multirow{2}{*}{\multicolumn{2}{|c|}{$\begin{array}{c}\text { Total } \\
\mathrm{n}=714\end{array}$}} & \multirow{2}{*}{\multicolumn{2}{|c|}{$\begin{array}{l}\text { GIRLS } \\
\mathrm{n}=284(39.8 \%)\end{array}$}} & \multirow{2}{*}{\multicolumn{2}{|c|}{$\begin{array}{l}\text { BOYS } \\
n=430(60.2 \%)\end{array}$}} & \multirow[b]{3}{*}{$\chi^{2}$} & \multirow[b]{3}{*}{$\mathrm{p}$} \\
\hline & & & & & & & & \\
\hline & $\mathrm{n}$ & $\%$ & $\mathrm{n}$ & $\%$ & $\mathrm{n}$ & $\%$ & & \\
\hline Tobacco & 117 & 16.38 & 17 & 14.52 & 100 & 85.47 & 37.231 & 0.000 \\
\hline Cannabis & 48 & 6.72 & 2 & 1.7 & 46 & 95.83 & 27.24 & 0.000 \\
\hline Alcohol & 42 & 53.88 & 3 & 2.56 & 39 & 92.86 & 19.838 & 0.000 \\
\hline
\end{tabular}


Table 3. Prevalence of HADS (Anxiety and Depressive Disorders) in both populations: PAS consumers and non-consumers.

\begin{tabular}{|c|c|c|c|c|c|c|c|c|c|c|}
\hline & \multicolumn{8}{|c|}{ HADS and consumption of psychoactive substances } & & \\
\hline & \multicolumn{2}{|c|}{ Non-Consumers } & \multicolumn{6}{|c|}{ Regular consumers } & & \\
\hline & \multicolumn{2}{|c|}{$\mathrm{n}=545(76.33 \%)$} & \multicolumn{6}{|c|}{$\mathrm{n}=169(23.66 \%)$} & & \\
\hline & & & \multicolumn{2}{|c|}{ Tobacco } & \multicolumn{2}{|c|}{ Cannabis } & \multicolumn{2}{|c|}{ Alcohol } & & \\
\hline & & & \multicolumn{2}{|c|}{$\mathrm{n}=117(39.8 \%)$} & \multicolumn{2}{|c|}{$\mathrm{n}=48(39.8 \%)$} & \multicolumn{2}{|c|}{$\mathrm{n}=42(39.8 \%)$} & \multirow[b]{2}{*}{$\mathrm{t}$} & \multirow[b]{2}{*}{$\mathrm{p}$} \\
\hline HADS & $\mathrm{n}$ & $\%$ & $\mathrm{n}$ & $\%$ & $\mathrm{n}$ & $\%$ & $\mathrm{n}$ & $\%$ & & \\
\hline Anxiety Disorders & & & & & & & & & 8.669 & $<0.001$ \\
\hline Absence of anxiety disorder & 443 & 81.28 & 64 & 54.70 & 34 & 70.83 & 29 & 69.05 & & \\
\hline Suspicious anxiety disorder & 59 & 10.83 & 34 & 29.06 & 10 & 20.83 & 9 & 21.43 & & \\
\hline Severe anxiety disorder & 43 & 7.89 & 19 & 16.24 & 4 & 8.33 & 4 & 9.2 & & \\
\hline Depressive disorders & & & & & & & & & 6.763 & $<0.001$ \\
\hline Absence of depressive disorders & 439 & 80.55 & 54.99 & 47.00 & 32 & 66.67 & 27 & 64.29 & & \\
\hline Suspicious depressive disorders & 72 & 13.21 & 40 & 34.19 & 10 & 20.83 & 9 & 21.43 & & \\
\hline Severe depressive disorders & 34 & 6.24 & 22 & 18.80 & 6 & 12.50 & 6 & 14.29 & & \\
\hline
\end{tabular}

\subsubsection{Depressive Disorders}

The results of this work show that consumer subjects appear more depressed than non-consumers $(t=6.763, p<0.001)$ : the majority of non-consumers (80.55\%) do not have depressive disorder, compared to about half $(47.53 \%)$ of tobacco users, about two-thirds (66.67\%) of cannabis users and $64.29 \%$ of alcohol users. Otherwise, just over one-tenth (13.21\%) of non-consumers have suspicious depressive disorders compared to just over one-third (34.19\%) of tobacco users and about one-fifth (20.83\%) of cannabis users and $21.43 \%$ of consumers; and a small proportion (6.24\%) of non-consumers have proven depressive disorders, compared with $18.8 \%$ of tobacco users, $12.5 \%$ of cannabis users and $14.29 \%$ of alcohol users (Table 3).

\subsubsection{Adolescent Depression Rating Scale (ADRS)}

Almost half of teenagers with PAS have a depressive tendency $(t=4.701, p<$ 0.001 ), as $46.14 \%$ had a score above 4 on the ADRS scale. A confirmed depression (ADRS score $\geq 8$ ) was found in only $8.28 \%$ of adolescents and only $54.43 \%$ presented no risk of depressive disorders. Regarding non-users, $62.01 \%$ do not present any risk of depression, $22.94 \%$ present a moderate risk and only $6.05 \%$ present a significant risk to depression (Table 4).

\section{Discussion}

The present school-based survey of 714 secondary school students qualifying for the Kenitra region aimed to explore the current state of consumption of the main psychoactive substances (tobacco, cannabis, alcohol) among schoolchildren, their relationships reciprocal and possible links with psychological suffering of anxious or depressive type. Moreover, the results collected have made it possible to establish a profile of the consumers of psychoactive substances. 
Table 4. Prevalence of the ADRS scale among the two populations: consumers and non-consumers of PAS in schools.

\begin{tabular}{|c|c|c|c|c|c|c|}
\hline \multirow{3}{*}{$\begin{array}{l}\text { ADRS and } \\
\text { consumption of } \\
\text { psychoactive } \\
\text { substances }\end{array}$} & \multicolumn{5}{|c|}{ ADRS and consumption of psychoactive substances } & \\
\hline & \multicolumn{2}{|c|}{ Non-Consumers } & \multicolumn{3}{|c|}{ Regular consumers } & \\
\hline & \multicolumn{2}{|c|}{$\mathrm{n}=545(76.33 \%)$} & \multicolumn{2}{|c|}{$\mathrm{n}=169(23.66 \%)$} & & \\
\hline ADRS & & & & & $\mathrm{t}$ & $\mathrm{p}$ \\
\hline Absence of risk & 388 & 62.01 & 92 & 54.43 & & \\
\hline Moderate risk & 125 & 22.94 & 64 & 37.86 & 4.701 & 0.001 \\
\hline High risk & 32 & 5.87 & 14 & 8.28 & & \\
\hline
\end{tabular}

Indeed, the adolescent population studied, appears more depressed and more anxious and show levels of consumption of high psychoactive substances.

\subsection{Consumption of Psychoactive Substances}

The prevalence of smoking in the group of adolescents in the Kenitra region is $16.38 \%$. This prevalence is similar to that of school-based studies, particularly among secondary school and college students, who show smoking prevalence ranging from $6.5 \%$ to $15.4 \%$ [13] [15] [16]. As well as that report in the National Program for the Evaluation of Acquired Students (NPEA) report 2016 [21] which is $15 \%$. However, this prevalence remains inferior to those reported by international studies, which are 30\% [22], 34\% [23] and 32.4\% [10]. In the sample studied, $6.72 \%$ of the students reported having used cannabis and $5.88 \%$ of the alcohol regularly during the last 30 days, these results were close to the one reported in the MEDSPA 2014 [12] survey prevalence of cannabis and alcohol during the last 30 days, were successively $4.7 \%$ and $3 \%$ ). However, the NPEA (2016) [21] has higher prevalence: 13\% use drugs within the establishment and $10 \%$ use alcohol. In addition, the 2014 ESCAPAD survey [10] interviewing 26,351 French adolescents shows a higher regular use of alcohol, which concerns $12.3 \%$ of respondents, and comparable for that of cannabis use $4 \%$.

Studies of the prevalence of psychoactive substance use clearly show that not all types of psychoactive substances consumed in the same way or at the same age. This is all the more important to take into account that the trajectory of changes in consumption depends on the type of psychoactive substance consumed [24] [25] [26].

\subsection{Anxiety-Depressive Disorders}

The two tests selected for the search for depressive syndrome (HADS and ADRS), are designed to identify a depressive syndrome in adolescents and measure its intensity. They give an assessment of the depressive symptomatology according to three cases: absence of disorders or of risk, susceptible disorders or moderate risk and severe disorders or risk.

However, whatever the test administered, our study, like most surveys conducted in children and adolescents, shows prevalences affirming the existence of 
depressive symptomatology at this period of life. Thus, for the non-consumer population the absence of depressive symptomatology estimated between $41.10 \%$ and $80.55 \%$; suspicious disorders between $13.21 \%$ (HAD-D) and $22.94 \%$ (ADRS) and severe disorders at $6.24 \%$ (HAD-D). However, for teenagers, the absence of disorders concerns $66.67 \%$ (HAD-D); suspicious disorders at 20.83\% (HAD-D); while severe disorder is estimated to be between $8.28 \%$ (ADRS). These results remain close to that of the national survey of the Ministry of Public Health, which reported that $48.9 \%$ of Moroccans suffer or have already suffered from mental disorders [27]. Moreover, that which appears in the report of the National Council of Human Rights in 2012, which announces that $48 \%$ of Moroccans suffer from mental disorders, $26.5 \%$ of them are victims of depressions [28].

Although the depressive signs are present in the adolescent population as in the literature, the lack of data concerning Moroccan adolescents suffering from such a disorder doesn't allow comparing the results obtained with other adolescents presenting the same socio-cultural framework. Moreover, depressive and anxiety disorders represent the most frequent psychiatric diagnosis in children and adolescents [29] [30]. Hence the importance of their evaluation in this study. They are generally comorbid and overlap with symptoms, causes and consequences [31]. Furthermore, the result obtained concerning the prevalence of anxiety symptomatology confirms the suffering of the adolescents of such a disorder, independently of the consumption of the PAS. Since among the non-consuming subjects this prevalence is estimated between $10.83 \%$ for the suspect disorders and $7.89 \%$ for the troubled disorders; these values belong to the interval reported by several studies and vary between $8 \%$ and $30 \%$ during life [32].

Otherwise, a comparison of the two groups of adolescents studied reveals that the presence of anxious symptomatology is significantly greater in teenagers who use PAS ( $p=0.001)$. This result is confirmed by numerous studies [23] [33] [34]. Thus, the research of Sonntag et al. (2000) [35] find that in social phobia, which is the most common pathology among anxiety disorders, smoking is twice as common and often associated with alcohol. Moreover, comorbidity, between cannabis use and anxiety symptoms, has been found in several epidemiological and clinical studies in adolescents. There is a link between the use of psychoactive substances and psychopathological symptoms such as anxiety [36]. On the other hand, the lack of an apparent relationship between cannabis use and anxiety does not exclude that anxiety may favor consumption, as this possibility may be masked by the anxiolytic effect of cannabis [37], and depressive disorders represent the common mental health problem in adolescents worldwide [38]. According to the study of Flament et al. (2001) [39], 20\% of adolescents may have depressive symptomatology, too often considered a transient adolescent crisis.

While in France in 2014, it is estimated that a quarter of adolescents aged 17 had a depressive syndrome (moderate for $20.8 \%$ and severe for $5.3 \%$ of them) 
[40]. These results are similar to those of the present study, since (according to the evaluation of the HAD-D test) the assessment of the depressive symptomatology in adolescents who do not consume PAS is estimated at $13.21 \%$ for suspicious disorders and $6.24 \%$ for proven troubles.

\subsection{Comorbidity Depression and Consumption of Psychoactive Substances}

The comorbidity between depressive symptomatology and PAS consumption has been the subject of several epidemiological studies [23] [41] [42]. In addition, diagnosis of depressive or anxious states in childhood or adolescence is associated with a greater risk of substance abuse [41] [43]. Thus, depression at a young age is positively associated with substance abuse [44] [45]. Gomes found a strong relationship between psychoactive substance use and depression in adolescence [46]. Other clinical studies in adolescents have reported the association between substance use disorders, major depression and personality disorders [47]. In this regard, the results of the various scales (HAD-D, ADRS) to identify the prevalence of adolescents possibly depressed have revealed that teenagers consuming PPS appear more depressed since the expression of depressive symptomatology is more important in them. Moreover, a positively significant difference in the scores of each tests in the PAS and non-consumer consumers noted.

On the other hand, many studies highlight the co-occurrence of depressive disorders and a significant consumption of psychoactive substances in adolescence [48] [49] [50] [51]. This co-occurrence of depression and substance abuse is associated with greater severity and duration of both problems [45] [52]. Moreover, the results of Janssen's work show in 17-year-olds a marked gradient between substance use level and depressive severity [40]. When regular polydrug consumption of tobacco, alcohol and/or cannabis increases significantly with the degree of severity of depression in the adolescent population, co-occurrence of these uses does not mean that they are concomitant [40].

Otherwise, the observation of criteria of anxiety and depression is more frequent among smokers than non-smokers [32] [33] [34]. Moreover, one study found an increased risk of depression among tobacco users, a significant risk of increasing tobacco use with depression, and the existence of common genetic [53] and neurobiological factors predisposing both to smoking disorders [54]. While other research on the adolescent population shows that depressive symptomatology in adolescence is associated with smoking and alcohol abuse [55] [56], and that depressed adolescents speculate that the use of substances can conclude benefits [57]. In this regard, it noted in the results obtained by the HAD-D test that adolescent smokers had the highest scores on the expression of depressive states and that cannabis users had the lowest; this can either reveal the antidepressant effect of cannabis, or suggest that depressive symptomatology tends to protect against the risk of consumption. It may also result from these two effects, with some depressed subjects using cannabis as self-medication and 
other depressed subjects avoiding cannabis use more than non-depressed ones, due to anxiety, a tendency to guilt, or diminished ability to seek out experiences of pleasure [37].

This finding does not contradict the positive links between cannabis use and the presence of depressive symptomatology both in the present work and in other studies such as that of Troisi which showed that the frequency of psychiatric disorders, especially depressive disorders and anxious, was correlated with the importance of cannabis use in young adults [36]. Or the longitudinal study in adults of Bovasso, which showed that subjects without depressive symptoms at baseline and using cannabis had a 4-fold higher risk of developing depression than subjects without initial depression who did not consume alcohol cannabis, as well as psychiatric symptoms or disorders [58].

\section{Conclusions}

This work will increase the scientific evidence on the links between anxiety-depressive disorders and ASA consumption in schooled adolescents in the city of Kenitra, by providing important points of reflection regarding the psychic vulnerability of adolescent PAS consumers.

These results encourage an emphasis on the school's role in early detection of adolescent-specific pathologies such as anxiety and depression. As well as the development of the strategy of prevention of the consumption of the PAS, and the care of the pupils presenting anxious or depressive symptomatology. In addition, further longitudinal studies would be needed to establish causal links between anxiety, depression, and PAS use.

\section{References}

[1] Lansford, J.E., Erath, S., Tianyi, Y.U., Pettit, G.S., Dodge, K.A. and Bates, J.E. (2008) The Developmental Course of Illicit Substance Use from Age 12 to 22: Links with Depressive, Anxiety, and Behavior Disorders at Age 18. Journal of Child Psychology and Psychiatry and Allied Disciplines, 49, 877-885. https://doi.org/10.1111/j.1469-7610.2008.01915.x

[2] Lubman, D.I., Allen, N.B., Rogers, N., Cementon, E. and Bonomo, Y. (2007) The Impact of Co-Occurring Mood and Anxiety Disorders among Substance-Abusing Youth. Journal of Affective Disorders, 103, 105-112. https://doi.org/10.1016/j.jad.2007.01.011

[3] Walkup, J.T., Albano, A.M., Piacentini, J., Birmaher, B., Compton, S.N., Sherrill, J.T., et al. (2008) Cognitive Behavioral Therapy, Sertraline, or a Combination in Childhood Anxiety. New England Journal of Medicine, 359, 2753-2766. https://doi.org/10.1056/NEJMoa0804633

[4] Wolitzky-Taylor, K., Bobova, L., Zinbarg, R.E., Mineka, S. and Craske, M.G. (2012). Longitudinal Investigation of the Impact of Anxiety and Mood Disorders in Adolescence on Subsequent Substance Use Disorder Onset and Vice Versa. Addictive Behaviors, 37, 982-985. https://doi.org/10.1016/j.addbeh.2012.03.026

[5] Horowitz, J.L. and Garber, J. (2006) The Prevention of Depressive Symptoms in Children and Adolescents: A Meta-Analytic Review. Journal of Consulting and 
Clinical Psychology, 74, 401-415. https://doi.org/10.1037/0022-006X.74.3.401

[6] Dierker L., Rose, J., Selya, A., Piasecki, T.M., Hedeker, D. and Mermelstein, R. (2015) Depression and Nicotine Dependence from Adolescence to Young Adulthood. Addictive Behaviors, 41, 124-128. https://doi.org/10.1016/j.addbeh.2014.10.004

[7] Bauman, A. and Phongsavan, P. (1999) Epidemiology of Substance Use in Adolescence: Prevalence, Trends and Policy Implications. Drug and Alcohol Dependence, 55, 187-207. https://doi.org/10.1016/S0376-8716(99)00016-2

[8] Johnston, L.D., O’Malley, P.M., Bachman, J.G. and Schulenberg, J.E. (2010) Monitoring the Future: National Results on Adolescent Drug Use. Overview of Key Findings, April, 2006. http://ncadistore.samhsa.gov/catalogNIDA/

[9] Smart, R.G. and Ogborne, A.C. (2000) Drug Use and Drinking Among Students in 36 Countries. Addictive Behaviors, 25, 455-460. https://doi.org/10.1016/S0306-4603(99)00013-1

[10] Spilka, S., Le Nézet, O., Beck, F., Ehlinger, V. and Godeau, E. (2012) Alcohol, Tobacco and Cannabis during the "Middle School". Trends, the French Observatory of Drugs and Drug Addiction, 80.

[11] Beck, F. and Legleye, S. (2009) Sociology and Epidemiology of Adolescents' Psychoactive Substance Use. Encephale, S6, 190-201. https://doi.org/10.1016/S0013-7006(09)73470-0

[12] Toufiq, J., El Omari, F. and Sabir M. (2014) Drug Use. Drug Use among Moroccan Students. School Survey, Medspad Maroc.

[13] Kaoutar, K., Hilali, M.K. and Loukid, M. (2012) Smoking and Related Factors of Adolescents in the City of Marrakech (Morocco). Antropo, 28, 97-104.

[14] Zarrouq, B. Bendaou, K. Rammouz, I., Najdi, A., Nejjari, C. and El Rhazi, K. (2014) The Determinants of the Use of Psychoactive Substances among Moroccan Middle and High School Students, Regions of Fès-Boulemane and Taza-Taounate-El Hoceima. Morocco VIth International Congress of Epidemiology/Revue d'Épidémiologie et de Santé Publique, 62S, S171-S212.

[15] Achbouk, A. (2002) Smoking in Schools in Marrakech. Ph.D. Thesis in Medicine, Rabat.

[16] Bensalah, M. (2010) Knowledge, Attitudes and Behavior of Schoolchildren vis-à-vis Smoking in the Prefecture of Oujda. Thesis Doctorate, Sidi Mohamed Ben Abdellah University, Morocco.

[17] Revah-Levy, A., Birmaher, B., Gasquet, I. and Falissard, B. (2007) The Adolescent Depression Rating Scale (ADRS): A Validation Study. BMC Psychiatry, 7, No. 2. https://doi.org/10.1186/1471-244X-7-2

[18] Zigmond, A.S. and Snaith, R.P. (1983) The Hospital Anxiety and Depression Scale. Acta Psychiatrica Scandinavica, 67, 361-370. https://doi.org/10.1111/j.1600-0447.1983.tb09716.x

[19] Wing Jiccooferj, J.E. and Smcrosus, N. (1974) The Measurement and Classification of Psychiatric Symptoms. Cambridge University Press, London.

[20] Snaith, R.P., Baugh, S.J., Clayoev, A.D. and Husain, A. (1982) The Clinical Anxiety Scale an Instrument Derived from the Hamilton Anxiety Scale. The British Journal of Psychiatry, 141, 518-523. https://doi.org/10.1192/bjp.141.5.518

[21] NPEA (2016) The National Program for the Evaluation of Acquired Students of the Core Curriculum, Morocco.

[22] Legleyel, S., Spilka, S. and Le Nezet, O. (2007) Drugs in Adolescence in 
2005-Levels, Contexts of Use and Developments at 17 in France-Results of the Fifth National ESCAPAD Survey. French Observatory of Drugs and Drug Addiction.

[23] Chéron-Launay, M., et al. (2011) Identifying Addictive Behaviors in Adolescents: High School Student Survey. Archives de Pédiatrie, 18, 737-744.

https://doi.org/10.1016/j.arcped.2011.04.019

[24] Becker, S.P., Luebbe, A.M. and Langberg, J.M. (2012) Co-Occurring Mental Health Problems and Peer Functioning among Youth with Attention-Deficit/Hyperactivity Disorder: A Review and Recommendations for Future Research. Clinical Child and Family Psychology Review, 15, 279-302. https://doi.org/10.1007/s10567-012-0122-y

[25] Flory, K., Lynam, D., Milich, R., Leukefeld, C. and Clayton, R. (2004) Early Adolescent through Young Adult Alcohol and Marijuana Use Trajectories: Early Predictors, Young Adult Outcomes, and Predictive Utility. Development and Psychopathology, 16, 193-213. https://doi.org/10.1017/S0954579404044475

[26] Martino, S., Ellickson, P. and McCaffrey, D. (2008) Developmental Trajectories of Substance Use from Early to Late Adolescence: A Comparison of Rural and Urban Youth (Report). Journal of Studies on Alcohol and Drugs, 69, 430-442. https://doi.org/10.15288/jsad.2008.69.430

[27] National Survey of the Ministry of Public Health (2006) Epidemiological Situation of Mental Disorders and Drug Addiction in Morocco. Medical Reference, No. 9.

[28] Report of the National Council of Human Rights (NCHR) (2012) Mental Health and Human Rights, Morocco.

[29] Merikangas, K.R., He, J., Burstein, M., Swanson, S.A., Avenevoli, S., Cui, L. and Swendsen, J. (2010) Lifetime Prevalence of Mental Disorders in US Adolescents: Results from the National Comorbidity Study-Adolescent Supplement (NCS-A). Journal of the American Academy of Child and Adolescent Psychiatry, 49, 980-989. https://doi.org/10.1016/j.jaac.2010.05.017

[30] Denis, H. and Baghdadli, A. (2016) Anxiety Disorder in Children and Adolescents. Psychiatry, 13, 1-10.

[31] Garber, J. and Weersing, V.R. (2010) Comorbidity of Anxiety and Depression in Youth: Implications for Treatment and Prevention. Clinical Psychology: Science and Practice, 17, 293-306. https://doi.org/10.1111/j.1468-2850.2010.01221.x

[32] Costello, E.J., Mustillo, S., Erkanli, A., Keeler, G. and Angold, A. (2003) Prevalence and Development of Psychiatric Disorders in Childhood and Adolescence. Archive of General Psychiatry, 60, 837-844. https://doi.org/10.1001/archpsyc.60.8.837

[33] John, U., Meyer, C., Rumpf, H., et al. (2004) Smoking, Nicotine Dependence and Psychiatric Comorbidity-A Population-Based Study Including Smoking Cessation after Three Years. Drug Alcohol Depend, 76, 287-295.

https://doi.org/10.1016/j.drugalcdep.2004.06.004

[34] Schumann, A., Hapke, U., Meyer, C., et al. (2004) Prevalence, Characteristics, Associated Mental Disorders and Predictors of DSM-IV Nicotine Dependence. European Addiction Research, 10, 29-34. https://doi.org/10.1159/000070983

[35] Sonntag, H., Wittchen, H.U., Hofler, M., et al. (2000) Are Social Fears and DSM-IV Social Anxiety Disorder Associated with Smoking and Nicotine Dependence in Adolescents and Young Adults. European Psychiatry, 15, 67-74. https://doi.org/10.1016/S0924-9338(00)00209-1

[36] Troisi, R., Weiss, H.A., Hoover, R.N., Potischman, N., Swanson, C.A., Brogan, D.R., Coates, R.J., Gammon, M.D., Malone, K.E., Daling, J.R. and Brinton, L.A. (1998) 
Pregnancy Characteristics and Maternal Risk of Breast Cancer. Epidemiology, 9, 641-647.

[37] Chabrol, H., Duconge, E., Roura, C. and Casas, C. (2004) Relations Entre les symptomatologies anxieuse, dépressive et limite et la consommation et la dépendance au cannabis chez l'adolescent et le jeune adulte. Encéphale, 30, 141-146. https://doi.org/10.1016/S0013-7006(04)95424-3

[38] Lopez, A.D., Mathers, C.D., Ezzati, M., Murray, C.J.L. and Jamison, D.T. (2006) Global Burden of Disease and Risk Factors. Oxford University Press, New York. https://doi.org/10.1596/978-0-8213-6262-4

[39] Flament, M.F., Cohen, D., Choquet, M., Jeammet, P. and Ledoux, S. (2001) Phenomenolgy, Psychosocila Correlates, and Treatment Seeking in Major Depression and Dysthymia of Adolescence. Journal of the American Academy of Child and Adolescent Psychiatry, 40, 1070-1078.

[40] Janssen, E., Spilka, S. and Beck, F. (2017) Suicide, santé mentale et usages de substances psychoactives chez les adolescents français en 2014. Revue d'Épidémiologie et de Santé Publique, 65, 409-417.

[41] Thapar, A., Collishaw, S., Pine, D.S. and Thapar, A.K. (2012) Depression in Adolescence. The Lancet, 379, 1056-1067. https://doi.org/10.1016/S0140-6736(11)60871-4

[42] Cottencin, O. (2009) Dépressionssévèreset Addictions Severe Depression and Addictions. L'EncéphaleSupplément, 7, S264-S268. https://doi.org/10.1016/S0013-7006(09)73483-9

[43] Kim, J., Chung, Y.D., Park, D.Y., Choi, S., Shin, D.W., Soh, H., Lee, H.W., Son, W., Yim, J., Park, C.S., Kernan, M.J. and Kim, C. (2003) A TRPV Family Ion Channel Required for Hearing in Drosophila. Nature, 424, 81-84. https://doi.org/10.1038/nature01733

[44] O’Neil, K.A., Conner, B.T. and Kendall, P.C. (2011) Internalizing Disorders and Substance Use Disorders in Youth: Comorbidity, Risk, Temporal Order, and Implications for Intervention. Clinical Psychology Review, 31, 104e12.

[45] Mason, W.A., Hitchings, J.E. and Spoth, R.L. (2007) Emergence of Delinquency and Depressed Mood throughout Adolescence as Predictors of Late Adolescent Problem Substance Use. Psychology of Addictive Behaviors, 21, $13 \mathrm{e} 24$.

[46] Gomes, S.T., Gomes, S.T., Frota, M.V., Aguiar, M.B.P. and Nogueira, M.B. (2012) Substance Abuse and Depression in Adolescents. Neuropsychiatrie de Penfanceet de Padolescence, 60, S197-S253.

[47] Spielberger, D.D., Gorsuch, R.L. and Lushene, R.E. (1970) Siuie-Trait Anxiety, Inventory, bfunual. Consulting Psychologists Press, Palo Alto.

[48] Evans, E., Hawton, K. and Rodham, K. (2005) Suicidal Phenomena and Abuse in Adolescents: A Review of Epidemiological Studies. Child Abuse \& Neglect, 29, 45-58. https://doi.org/10.1016/j.chiabu.2004.06.014

[49] Wilcox, H.C., Conner, K.R. and Caine, E.D. (2004) Association of Alcohol and Drug Use Disorders and Completed Suicide: An Empirical Review of Cohort Studies. Drug and Alcohol Dependence, 76, S9-S11.

[50] Deykin, E.A. and Buka, S.L. (1994) Suicidal Ideation and Attempts among Chemically Dependent Adolescents. American Journal of Public Health, 84, 634-639. https://doi.org/10.2105/AJPH.84.4.634

[51] Beck, F., Guignard, R., Du Roscoat, E. and Saras, T. (2011) Suicide Attempts and Suicidal Thoughts in France in 2010. BEH, 47-48, 488-492. 
[52] Lewinsohn, P.M., Rhode, P. and Seeley, J.R. (1995) Adolescent Psychopathology: III. The Clinical Consequences of Comorbidity. Journal of the American Academy of Child and Adolescent Psychiatry, 34, 510-519. https://doi.org/10.1097/00004583-199504000-00018

[53] Lyons, M., Hitsman, B., Xian, H., et al. (2008) A Twin Study of Smoking, Nicotine Dependence, and Major Depression in Men. Nicotine \& Tobacco Research, 10, 97-108. https://doi.org/10.1080/14622200701705332

[54] Brody, C.L., Hamer, D.H. and Haaga, D.A. (2005) Depression Vulnerability, Cigarette Smoking, and the Serotonin Transporter Gene. Addictive Behaviors, 30, 557-566. https://doi.org/10.1016/j.addbeh.2004.08.005

[55] Haarasilta, L.M., Marttunen, M.J., Kaprio, J.A. and Aro, H.M. (2004) Correlates of Depression in a Representative Nationwide Sample of Adolescents and Young Adults. European Journal of Public Health, 14, 2805.

https://doi.org/10.1093/eurpub/14.3.280

[56] Zhou, X., Qin, B., Del Giovane, C., Pan, J., Gentile, S., Liu, Y. and Xie, P. (2015) Efficacy and Tolerability of Antidepressants in the Treatment of Adolescents and Young Adults with Depression and Substance Use Disorders: A Systematic Review and Meta-Analysis. Addiction, 110, 38e48. https://doi.org/10.1111/add.12698

[57] Siennick, S.E., Widdowson, A.O., Woessner, M.K., Feinberg, M.E. and Spoth, R.L. (2016) Risk Factors for Substance Misuse and Adolescents' Symptoms of Depression. Society for Adolescent Health and Medicine.

[58] Bovasso, G.B. (2001) Cannabis Abuse as a Risk Factor for Depressive Symptoms. The American Journal of Psychiatry, 158, 2033-2037.

https://doi.org/10.1176/appi.ajp.158.12.2033 